Pacific Journal of Mathematic 


\section{LINEAR INEQUALITIES AND QUADRATIC FORMS}

JERRY W. GADDUM

1. Introduction. There are known criteria for a quadratic form to be positive definite, and criteria for a system of linear inequalities to have a solution. In this paper the two problems are shown to be related. The principal theorem is Theorem 5.1.

2. Definitions and Notation. We will consider a quadratic form

$$
Z(x) \equiv \sum_{1}^{n} a_{i j} x_{i} x_{j}, \text { with } a_{i j}=a_{j i},
$$

and ask whether it is positive in the first orthant, i.e., whether it is positive for non-negative values of the $x_{i}$.

If $Z(x)>0$ for $x \geqq 0$, we call it conditionally definite and if $Z(x) \geqq$ for $x \geqq 0$, we call it conditionally semi-definite. (Since we will only be concerned with positive definiteness, we will omit the word "positive" throughout the paper.) Finally, if $Z(x) \geqq 0$ when $x \geqq 0$ and $Z(x)>0$ when $x>0$, we call $Z(x)$ conditionally almost-definite.

As a matter of notation, we recall that $A x \geq 0$ or $x \geq 0$ means that at least one component of the vector in question is positive.

In discussing $Z(x)$ we shall have occasion to refer to the form obtained by setting $x_{k_{1}}, x_{k_{2}}, \cdots, x_{k_{s}}$ equal to zero, that is, the form

$$
\sum_{i, j \neq k_{1}, \cdots, k_{s}} a_{i j} x_{i} x_{i j}
$$

We shall call this a principal minor of $Z(x)$ and denote it $Z_{k_{1} \cdots k_{s}}(x)$. In referring to the corresponding matrix, $A^{k_{4}, \ldots k_{s}}$ we will assume $x$ has the appropriate number of components when we write $A^{k_{1} \cdots k_{s}} x$.

3. Quadratic forms in the first orthant. We first prove a theorem which is not strictly necessary but may be some intrinsic interest. It concerns the game whose matrix is $A=\left(a_{i j}\right)$ and whose value is $v$. (For completeness we remind the reader of the following definition of the value $v$ of a game with matrix $B=\left(b_{i j}\right), i=1, \cdots, m ; j=1, \cdots, n$. Let $X$ be the set of vectors $x=\left(x_{1}, \cdots, x_{m}\right)$ with $x_{1} \geqq 0$ and $\sum_{1}^{m} x_{i}=1$; $Y$ the set of $y=\left(y_{1}, \cdots, y_{n}\right)$ with $y_{j} \geqq 0$ and $\sum_{1}^{n} y_{j}=1$. Then it can be shown that

$$
\max _{x \in X} \min _{y \in Y} \sum b_{i j} x_{i} y_{j}=\min _{y \in Y} \max _{x \in X} \sum b_{i j} x_{i} x_{j},
$$

and this quantity is called the value of the game with matrix $B$ ).

Received December 9, 1957. 
THEOREM 3.1. Suppose each principal minor of $Z(x)$ is conditionally definite. Then in order that $Z(x)$ be conditionally definite, it is necessary and sufficient that $v>0$.

Proof. Suppose $v \leqq 0$. Then there is a $y \geqq 0$ with $A y \leqq 0$. But

$$
Z(y)=\sum_{i=1}^{n}\left(\sum_{j=1}^{n} a_{i j} y_{j}\right) y_{i} \leqq 0 .
$$

This shows the necessity.

Suppose, now, that $v>0$. Then there is a vector $\bar{x}$ with $\bar{x} \geqq 0$ and $A \bar{x}>0$. Every vector $x \geqq 0$ can be written as a convex combination of $k \bar{x}, k>0$, and some vector $x^{\prime}$, with $x^{\prime} \geqq 0$ and $x^{\prime}$ in one of the coordinate planes. That is, for any $x \geqq 0, x=\lambda k \bar{x}+(1-\lambda) x^{\prime}, k>0$ and $0 \leqq \lambda \leqq 1$.

We note the fact that, for any $u, v$,

$$
\begin{aligned}
& Z[\lambda u+(1-\lambda) v]=\sum a_{i j}\left[\lambda u_{i}+(1-\lambda) v_{i}\right]\left[\lambda u_{j}+(1-\lambda) v_{j}\right] \\
& =\lambda^{2} \sum a_{i j} u_{i} u_{j}+2 \lambda(1-\lambda) \sum a_{i j} u_{i} v_{j}+(1-\lambda)^{2} \sum a_{i j} v_{i} v_{\jmath} .
\end{aligned}
$$

Thus,

(1) $Z[\lambda u+(1-\lambda) v]=\lambda^{2} Z(u)+(1-\lambda)^{2} Z(v)+2 \lambda(1-\lambda) \sum a_{i j} u_{i} v_{j}$.

Applying

$$
\text { (1) to } \begin{aligned}
x & =\lambda k \bar{x}+(1-\lambda) x^{\prime}, Z(x) \\
& =\lambda^{2} k^{2} Z(\bar{x})+(1-\lambda)^{2} Z\left(x^{\prime}\right)+2 \lambda(1-\lambda) k \sum a_{i j} \bar{x}_{i} x_{j}^{\prime} .
\end{aligned}
$$

Since every principal minor of $Z(x)$ is conditionally difinite, $Z\left(x^{\prime}\right)>0$. Since $\sum a_{i j} \bar{x}_{i}>0, j=1, \cdots, n, Z(\bar{x})>0$ and $\sum a_{i j} \bar{x}_{i} x_{j}^{\prime}>0$. Therefore, $Z(x)>0$ for $x>0$ and the sufficiency is proved.

We can state the following theorem, the proof of which is almost identical with the proof of Theorem 3.1.

THEOREM 3.2. If each principal minor of $Z(x)$ is conditionally semidefinite, then $Z(x)$ is conditionally semi-definite if and only if $v \geqq 0$.

For symmetry we state the foregoing as theorems on systems of linear inequalities.

THEOREM 3.3. Suppose each principal minor of $Z(x)$ is conditionally definite. Then the system $A x>0, x \geqq 0$ has solutions if and only if $Z(x)$ is conditionally definite.

THEOREM 3.4. Suppose each principal minor of $Z(x)$ is conditionally semi-definite. Then the system $A x \geqq 0, x \geqq 0$ has solutions if and only if $Z(x)$ is conditionally semi-definite.

These theorems raise the question of the relation between the form 
$Z(x)$ and the system $A x \geq 0, x \geq 0$. The following theorem answers it.

THEOREM 3.5. Suppose every principal minor of $Z(x)$ is conditionally semi-definite. Then the system $A x \geq 0, x \geq 0$ has solutions if and only if $Z(x)$ is conditionally almost-definite.

Proof. Suppose $A x \geq 0, x \geq 0$ is consistent and let $\bar{x}$ be a solution. As in the proof of Theorem 3.1, represent any $x>0$ by $x=\lambda k \vec{x}+(1$ $-\lambda) x^{\prime}$, where $\lambda, k$, and $x^{\prime}$ have the same significance as before. Then

$$
Z(x)=\lambda^{2} k^{2} Z(\bar{x})+(1-\lambda)^{2} Z\left(x^{\prime}\right)+2 \lambda(1-\lambda) k \sum a_{i j} \bar{x}_{i} x^{\prime} j .
$$

Now if $\bar{x}>0, Z(\bar{x})>0$, and $Z(x)$ will be if $\lambda>0$, that is, if $x>0$. On the other hand, if for every $i$ for which $\sum a_{i j} \bar{x}_{j}>0$ it happens that $\bar{x}_{i}=0, Z(\bar{x})=0$. However, if $x>0$ then $x_{i}^{\prime}>0$ if $\bar{x}_{i}=0$, and thus

$$
\sum a_{i j} \bar{x}_{i} x_{j}^{\prime}>0 \text {. }
$$

Thus in any case $Z(x)>0$ if $x>0$.

Now suppose $Z(x)$ conditionally almost-definite. Consider the convex hull, $A^{*}$, of the row vectors of $A$. If this contains a vector in the first orthant, then the system $A x>0, x>0$ has solutions.

If $A^{*}$ does not intersect the first orthant in any non-zero vector, then $A^{*}$ and the first orthant can be strictly separated by a hyperplane through the origin. One normal to this hyperplane, $y$, will lie interior to the first orthant.

Thus $A y \leqq 0$ and since $y>0, Z(y) \leqq 0$, contrary to the hypothesis that $Z(x)$ is conditionary almost-definite. Thus the theorem is proved.

4. Further development of Section 3. In the five theorems of $\S 3$, it is natural to try to replace the hypotheses concerning the principal minors of $Z(x)$ by some condition relating more directly to linear inequalities.

It is not difficult to verify that a quadratic form in two variables, $a x^{2}+2 b x y+c y^{2}$, is conditionally definite if and only if $a>0, c>0$ and either $b^{2}<a c$ or $b>0$. This is equivalent to the statement that

(1) $a x>0$

(2) $\quad c y>0$

(3) $a x+b y>0, b x+c y>0$

all have non-negative solutions. Proceeding by induction, we can state the following theorem.

THEOREM 4.1. A necessary and sufficient condition that $Z(x)=$ $\sum a_{i j} x_{i} x_{j}$ be conditionally definite is that for each principal minor $A^{k_{1}}$, $\ldots{ }^{k_{r}}$ of $A$, the system $A^{k_{1}}, \ldots{ }^{k_{r}} x>0 x \geqq 0$ be consistent. 
Clearly, Theorems 3.4 and 3.5 can be restated in this way but we forbear doing so here.

5. Positive Definite Forms. It is clear that to see whether a form $\sum a_{i j} x_{i} x_{j}$ is positive in the orthant where $x_{i_{1}}, x_{i_{2}}, \cdots, x_{i_{r}}$ are negative or zero, and the other unknowns positive or zero, we have only to multiply the $i_{1}$ th, $i_{2}$ th $, \cdots, i_{r}$ th rows and columns of $A \equiv\left(a_{i j}\right)$ by -1 and inquire whether the resulting form is conditionally definite. We may call the form $\sum b_{i j} x_{i} x_{j}$ obtained in this way a symmetric transform of $\sum a_{i j} x_{k} x_{j}$. Thus a quadratic form is positive definite if and only if every symmetric transform is conditionally definite.

THeOREM 5.1. A quadratic form $\sum a_{i j} x_{i} x_{3}$ is positive definite if and only if every system $B x>0, x \geqq 0$ is consistent where $B$ is a symmetric transform of a principal minor of $A$.

6. Linear Inequalities. Let $B$ be any $m \times n$ matrix and $C=B B^{T}$. In [1] it was shown that $B x \geq 0$ has solutions if and only if $C y \geq 0$, $y \geqq 0$ does. It can be shown that $B x>0$ has solutions if and only if $C y>0, y \geqq 0$ does.

Using these results, plus the foregoing discussion, we can summarize as follows :

THEOREM 6.1. The system $B x>0$ is consistent if and only if the

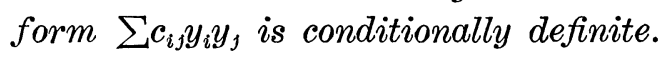

THEOREM 6.2. The system $B x \geq 0$ is consistent if and only it $\sum c_{i j} y_{i} y_{j}$ is conditionally almost-definite.

T. S. Motzkin in [2] has given a condition for a quadratic form to be conditionally semi-definite, the condition involving the signs of various determinants. No other discussion of this question is known to the writer.

\section{REFERENCES}

1. J. W. Gaddum, A theorem on convex cones with applications to linear inequalities, Proc. Amer. Math. Soc. Vol. 3, No. 6, pp. 957-960.

2. National Bureau of Standards Report 1818 (1952), 11-12.

University of FloRIDa, Michigan State University aNd OAK RIDGE NATIONAL LABORATORY 


\section{PACIFIC JOURNAL OF MATHEMATICS}

\section{EDITORS}

David Gilbarg

Stanford University

Stanford, California

R. A. Beaumont

University of Washington

Seattle 5, Washington

\author{
A. L. Whiteman
}

University of Southern California

Los Angeles 7, California

E. G. Straus

University of California

Los Angeles 24, California

\section{ASSOCIATE EDITORS}

\author{
E. F. BECKENBACH \\ C. E. BURGESS \\ M. HALL \\ E. HEWITT
}

\author{
A. HORN \\ V. GANAPATHY IYER \\ R. D. JAMES \\ M. S. KNEBELMAN
}

L. NACHBIN
I. NIVEN
T. G. OSTROM
H. L. ROYDEN

M. M. SCHIFFER

G. SZEKERES

F. WOLF

K. YOSIDA

\section{SUPPORTING INSTITUTIONS}

\author{
UNIVERSITY OF BRITISH COLUMBIA \\ CALIFORNIA INSTITUTE OF TECHNOLOGY \\ UNIVERSITY OF CALIFORNIA \\ MONTANA STATE UNIVERSITY \\ UNIVERSITY OF NEVADA \\ OREGON STATE COLLEGE \\ UNIVERSITY OF OREGON \\ UNIVERSITY OF SOUTHERN CALIFORNIA
}

\author{
STANFORD UNIVERSITY \\ UNIVERSITY OF UTAH \\ WASHINGTON STATE COLLEGE \\ UNIVERSITY OF WASHINGTON \\ AMERICAN MATHEMATICAL SOCIETY \\ CALIFORNIA RESEARCH CORPORATION \\ HUGHES AIRCRAFT COMPANY \\ THE RAMO-WOOLDRIDGE CORPORATION
}

Mathematical papers intended for publication in the Pacific Journal of Mathematics should be typewritten (double spaced), and the author should keep a complete copy. Manuscripts may be sent to any of the editors. All other communications to the editors should be addressed to the managing editor, E. G. Straus at the University of California, Los Angeles 24, California.

50 reprints per author of each article are furnished free of charge; additional copies may be obtained at cost in multiples of 50 .

The Pacific Journal of Mathematics is published quarterly, in March, June, September, and December. The price per volume (4 numbers) is $\$ 12.00$; single issues, $\$ 3.50$. Back numbers are available. Special price to individual faculty members of supporting institutions and to individual members of the American Mathematical Society: $\$ 4.00$ per volume; single issues, $\$ 1.25$.

Subscriptions, orders for back numbers, and changes of address should be sent to Pacific Journal of Mathematics, 2120 Oxford Street, Berkeley 4, California.

Printed at Kokusai Bunken Insatsusha (International Academic Printing Co., Ltd.), No. 6, 2-chome, Fujimi-cho, Chiyoda-ku, Tokyo, Japan.

\section{PUBLISHED BY PACIFIC JOURNAL OF MATHEMATICS, A NON-PROFIT CORPORATION}

The Supporting Institutions listed above contribute to the cost of publication of this Journal, but they are not owners or publishers and have no responsibility for its content or policies. 


\section{Pacific Journal of Mathematics}

\section{Vol. 8, No. 3 \\ May, 1958}

Michael Israel Aissen, A set function defined for convex plane domaines... . 383

Robert Ellis, Distal transformation groups ................... 401

Ciprian Foias, On a commutative extension of a commutative Banach algebra ....................................... 407

Jerry William Gaddum, Linear inequalities and quadratic forms ......... 411

Allen A. Goldstein and Elliott Ward Cheney, Jr., A finite algorithm for the solution of consistent linear equations and inequalities and for the Tchebycheff approximation of inconsistent linear equations...........

William L. Hart and T. S. Motzkin, Proof of the fundamental theorem on implicit functions by use of composite gradient corrections .......... 429

Henry Berge Helson, Conjugate series and a theorem of Paley .......... 437

Wu-Chung Hsiang, Abelian groups characterized by their independent subsets....................................... 447

John W. Lamperti, On the isometries of certain function-spaces ........ 459

Karel DeLeeuw and Walter Rudin, Extreme points and extremum problems

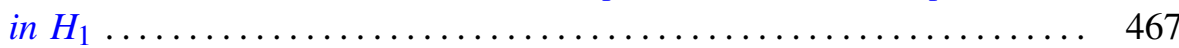

Eugene Lukacs, Some extensions of a theorem of Marcinkiewicz........ 487

George W. Mackey, Multiplicity free representations of finite groups ..... 503

Eben Matlis, Injective modules over Noetherian rings ............. 511

John William Neuberger, Continuous products and nonlinear integral equations

Lawrence Edward Payne and Hans F. Weinberger, New bounds for solutions of second order elliptic partial differential equations...

William T. Reid, A Prüfer transformation for differential systems ........ 575

Howard L. Rolf, The free lattice generated by a set of chains ...

K. M. Saksena, Inversion and representation theorems for a generalized

Laplace integral....................................... 597

Daniel Shanks, Two theorems of Gauss......................... 609

Paul Slepian, On the Lebesgue area of a doubled map ............... 613

Otto Szász and Nelson Paul Yeardley, Jr., The representation of an analytic function by general Laguerre series . ..................... 621

Alan C. Woods, On two-dimensional convex bodies ................. 635 